1. FCPS

Assistant Professor Gynecology \& Obstetrics

Nishtar Medical University, Multan.

2. FCPS

Associate Professor Gynecology \& Obstetrics

Nishtar Medical University, Multan.

3. FCPS

Assistant Professor Gynecology \& Obstetrics

Nishtar Medical University, Multan.

4. FCPS

Associate Professor Gynecology \& Obstetrics

Nishtar Medical University, Multan.

5. FCPS

Assistant Professor Gynecology \& Obstetrics

Nishtar Medical University, Multan.

6. FCPS

Assistant Professor Gynecology \& Obstetrics

Nishtar Medical University, Multan.

Correspondence Address:

Dr. Saima Yasmin Qadir

Assistant Professor Gynecology \&

Obstetrics

Nishtar Medical University, Multan

asharahmad71@hotmail.com

Article received on:

10/03/2020

Accepted for publication:

23/06/2020

\section{FREQUENCY OF ANEMIA AND CAUSATIVE RISK FACTORS IN PATIENTS PRESENTING TO TERTIARY CARE HOSPITAL: A CROSS SECTIONAL STUDY.}

\begin{abstract}
Saima Yasmin Qadir ${ }^{1}$, Hajira Sultana ${ }^{2}$, Saima Ashraf ${ }^{3}$, Shazia Siddiq $^{4}$, Asia Fayyaz $^{5}$, Shagufta Tabassum ${ }^{6}$

ABSTRACT... Objectives: To determine the frequency of anemia and its causative risk factors in patients attending the gynecology outpatient department of Nishtar Medical University and Hospital. Study Design: Cross sectional study. Setting: Gynecology Outpatient Department attendees of Nishtar Medical University and Hospital. Period: $1^{\text {st }}$ September to $31^{\text {st }}$ December 2019. Material \& Methods: Total 361 females between 19-49 years of age were enrolled and included those patients who consented to be tested for blood hemoglobin estimation. Results: Majority of patients $65 \%$ were between $19-35$ years of age and $34 \%$ were $36-49$ years of age. Frequency of pregnant patients and non-pregnant patients was $63.4 \%$ and $36.6 \%$. Frequency of anemia was $56.8 \%$, mean hemoglobin $10.48 \pm 1.18$ with mild, moderate and severe anemia were $36.8 \%, 17.2 \%$ and $2.8 \%$. Majority of females $82.9 \%$, never went to school and had primary education, $71.70 \%$ belong to very poor and poor socioeconomic status, $79.02 \%$ were multipara and $81.95 \%$ never and infrequently practiced the contraceptive methods. Conclusion: Frequency of anemia is very high in females presenting to tertiary care hospital being more common in younger age group. Frequent pregnancies, poor socioeconomic status and low level of educational attainment were the major determinants of anemia in females.
\end{abstract}

Key words: $\quad$ Anemia, Cross Sectional Study, Hemoglobin Level, Maternal Morbidity.

Article Citation: Qadir SY, Sultana H, Ashraf S, Siddiq S, Fayyaz A. Frequency of anemia and causative risk factors in patients presenting to tertiary care hospital: A cross sectional study. Professional Med J 2020; 27(9):1966-1970. DOI: 10.29309/TPMJ/2020.27.09.4641

\section{INTRODUCTION}

Anemia is defined as reduced level of hemoglobin that results in reduced oxygen carrying capacity of blood which precipitate multiple risks to mother and growing fetus. Iron deficiency anemia is the most prevalent anemia because of nutritional deficiency while other causes of anemia are genetic disorders like hemoglobinopathies and infectious diseases like malaria. ${ }^{1}$ Females during their reproductive years ${ }^{2}$ and children are affected more than males by anemia especially iron deficiency Anemia equally affects the fetus by causing small for gestation, preterm delivery, intrauterine growth restriction, low APGAR score, neonatal anemia and is also an independent reason of morbidity and mortality of all ages. ${ }^{3}$

Iron deficiency anemia is global public health problem being more prevalent in underdeveloped countries. Incidence of anemia is $9 \%$ in developed countries and $43 \%$ in underdeveloped countries. ${ }^{3}$ In Africa, anemia accounts 35\%, ${ }^{4}$ Africa and Asia contributes to $85 \%$ in causing absolute anemia burden globally ${ }^{5}$ almost two billion people are affected by anemia. ${ }^{6}$ In Pakistan, the $52-68 \%$ female population was anemic..$^{7,8}$ The known risk factors in causing anemia are uneducation societies, poor socioecomic status, fertility rates in women, multiparty, frequent mensturation and nonuse of contraceptives. ${ }^{9}$

World Health Assembly approved a comprehensive plan for the reduction of anemia in underdeveloped countries. Subsequently Pakistan with India, Ethopia, Yemen, Nigeria, Malawi and Uganda have systematically established the investigation plan to combat with this problem. ${ }^{10,11}$ In Uganda, Ministry Of Health has taken steps on improvement of nutritional interventions like production of bio fortified and 
iron rich crops, iron supplementation and breast feeding promotion, family planning, delayed cord clamping, prevention of malaria and worm infestation and promotion of hand hygiene. ${ }^{12,13}$

In Pakistan, secondary analysis of National Nutrition Survey Data reported that anemic mothers are more likely to have anemic children in Pakistan. So they have devised some vertical and horizontal programs to combat anemia. ${ }^{11}$ According to this survey, the prevalence of anemia in Pakistan is $18.1 \% .{ }^{11}$ We have performed this study in Nishtar medical university which the largest tertiary care center of South Punjab draining huge rural and urban area. Our aim was to observe the frequency of anemia in female patients attending the gynecology outdoor and have tried to find the reasons behind that. We have hypothesized that females during reproductive age groups, multiparous and with low level of education were more prone to develop anemia.

\section{MATERIAL \& METHODS}

Total 361 patients were enrolled in cross sectional study conducted in outpatient department of gynecology and obstetrics in Nishtar Medical University from $1^{\text {st }}$ September to $31^{\text {ST }}$ December 2019. Their brief history was taken after proper consent according to predesigned proforma to rule out the risk factors. All those females were included who consented for the blood to be tested. Patients with chronic lung disease, chronic liver disease and chronic kidney disease were excluded from study. Permission from ethical committee of Nishtar hospital was obtained. Blood test was done by obtainting the blood sample by finger prick method. Hemolglobin analysis was performed by portable Hemocueanalyser. Results were to provide to patients verbally and in written report form.

Frequency of anemia, severity of anemia and their stratification was performed against the risk factors like age, educational status, socioeconomic status, status of pregnancy, parity, and contraception to rule the causative risk factors. Anemia was marked as hemoglobin less than $11 \mathrm{gm} / \mathrm{dl}$ categorized into mild, moderate and severe anemia as 10-11 g/dl, 7-9.9 gm/dl and 4-6.9g/dl. Educational status was categorized as never went to school, primary education and more than primary education. Socioeconomic status was categorized as very poor (income less than Rs 10,000//month), poor (income Rs 10,000/ to $25,000 /-$ per month) and middle (income more than Rs 25,000/month). Contraception was categorized as never practiced, infrequently practiced and regularly practiced.

Stratification was performed to examine association between the dependent variable (anemia) and other variables. Pearson ChiSquare test was applied to examine the significant difference and $p$-value of $<0.05$ was considered significant. Mean \pm SD was used for the hemoglobin level.

\section{RESULTS}

Table-I showed that among total 361 female patients frequency of anemia was $56.8 \%$ where $36.8 \%, 17.2 \%$ and $2.8 \%$ were mild, moderate and severe anemia. Mean hemoglobin with standard deviation was $10.48 \pm 1.18 \mathrm{gm} / \mathrm{dl}$. TableII represented the causative socio-demographic variables as risk factors and their association with anemia. Majority of anemic patients $55.5 \%$ were from younger age group (19-35 years) and $44.5 \%$ were between $36-49$ years. The majority of anemic patients (95.17\%) attained either no education or were just had primary education. Anemia was more prevalent in very poor and poor patients (71.70\%). Majority of females (81.95\%) never practiced or infrequently practiced contraception. Females having two and more than two children were more anemic (79.01\%) than patients who were in their first pregnancy and had one child. Table-III represented females based on pregnancy status and duration of their pregnancy. Two hundred twenty nine patients were pregnant $(63.43 \%)$ and among them $60.28 \%$ were anemic and $94.20 \%$ were mild to moderately anemic and $46.28 \%$ were in their third trimester. 


\begin{tabular}{|l|c|c|}
\hline \multicolumn{1}{|c|}{ Anemia } & No. of Patients & Percentage (\%) \\
\hline Normal & 156 & 43.2 \\
\hline Mild & 133 & 36.8 \\
\hline Moderate & 62 & 17.2 \\
\hline Severe & 10 & 2.8 \\
\hline
\end{tabular}

Table-I. Frequency of anemia $(\mathrm{N}=361)$.

\begin{tabular}{|c|c|c|c|c|}
\hline Anemia & \multicolumn{3}{|c|}{ Age (Years) } & T-Test \\
\hline & $\begin{array}{l}19-35 \\
\text { years }\end{array}$ & \multicolumn{2}{|c|}{$36-49$ years } & \multirow{5}{*}{0.000} \\
\hline normal & 120 & \multicolumn{2}{|c|}{34} & \\
\hline Mild & 91 & & & \\
\hline Moderate & 22 & & & \\
\hline \multirow[t]{3}{*}{ severe } & 2 & & & \\
\hline & \multicolumn{3}{|c|}{ Education Status } & \multirow{6}{*}{0.000} \\
\hline & $\begin{array}{l}\text { Never } \\
\text { went to } \\
\text { school }\end{array}$ & primary & middle & \\
\hline normal & 105 & 25 & 24 & \\
\hline Mild & 69 & 74 & 5 & \\
\hline Moderate & 32 & 15 & 2 & \\
\hline \multirow[t]{3}{*}{ severe } & 5 & 2 & 3 & \\
\hline & \multicolumn{3}{|c|}{ Socioeconomic } & \multirow{6}{*}{0.000} \\
\hline & Very poor & poor & middle & \\
\hline normal & 36 & 62 & 58 & \\
\hline Mild & 17 & 67 & 49 & \\
\hline Moderate & 37 & 18 & 7 & \\
\hline \multirow[t]{3}{*}{ severe } & 7 & 1 & 2 & \\
\hline & \multicolumn{3}{|c|}{ Contraception } & \\
\hline & $\begin{array}{l}\text { Never } \\
\text { used }\end{array}$ & Infrequent & occasional & \multirow{5}{*}{0.000} \\
\hline normal & 124 & 29 & 3 & \\
\hline Mild & 74 & 38 & 21 & \\
\hline Moderate & 33 & 16 & 13 & \\
\hline \multirow[t]{3}{*}{ severe } & 5 & 2 & 3 & \\
\hline & \multicolumn{3}{|c|}{ Parity } & \\
\hline & one & $2-4$ & $>4$ & \multirow{5}{*}{0.000} \\
\hline normal & 36 & 53 & 67 & \\
\hline Mild & 8 & 36 & 89 & \\
\hline Moderate & 35 & 24 & 3 & \\
\hline severe & 0 & 8 & 2 & \\
\hline
\end{tabular}

Table-II. Socio-demographic factors associated with anemia $(n=361)$.

\begin{tabular}{|c|c|c|c|c|}
\hline Anemia & $\begin{array}{l}\text { Pregnancy } \\
\text { Status }\end{array}$ & & $\mathrm{T}-\mathrm{Te}$ & \\
\hline & $\begin{array}{c}\text { Pregnant } \\
(n=229)\end{array}$ & $\begin{array}{c}\text { Non- } \\
\text { pregnant } \\
(\mathrm{n}=132)\end{array}$ & \multirow{5}{*}{\multicolumn{2}{|c|}{0.004}} \\
\hline Normal & 91 & 65 & & \\
\hline Mild & 79 & 54 & & \\
\hline Moderate & 51 & 11 & & \\
\hline \multirow[t]{3}{*}{ Severe } & 8 & 2 & & \\
\hline & \multicolumn{3}{|c|}{ Duration of pregnancy $(n=229)$} & t-test \\
\hline & $\begin{array}{c}\text { Ist } \\
\text { Trimester }\end{array}$ & $\begin{array}{c}\text { Ilnd } \\
\text { Trimester }\end{array}$ & $\begin{array}{c}\text { Illrd } \\
\text { Trimester }\end{array}$ & \\
\hline Normal & 18 & 30 & 43 & \multirow{4}{*}{0.000} \\
\hline Mild & 9 & 4 & 66 & \\
\hline Moderate & 0 & 14 & 37 & \\
\hline Severe & 4 & 1 & 3 & \\
\hline
\end{tabular}

\section{DISCUSSION}

Anemia is the most prevalent disease in Africa and Asia affecting the males, females and children of all ages and having detrimental effects on their health. Frequency of anemia in our study is $56.8 \%$, Faseeh ${ }^{7}$ observed $66.8 \%$, Olivia reported $32 \%$ in Uganda ${ }^{9}$ and World Health Organization described that anemia affects $35 \%$ of Africal population. ${ }^{4}$ Indian State-level Disease Burden Initiative Malnutrition Collaborator described that $54.5 \%$ of females were between $15-49$ years of age. ${ }^{14}$ We observed that majority of females $44 \%$ suffer from mild and moderate anemia. Faseeh reported that $18.5 \%$ females had moderate anemia ${ }^{7}$. Aqsa reported that $58 \%$ of females between $18-28$ years were severely anemic. ${ }^{8}$

In our study we observed that young females were more anemic than females of more age during reproductive years. We observed 55.5\% were between 19-35 years, Aqsa reported that females between 18-28 years are more prone to develop anemia. ${ }^{8}$ Kassebaum observed that higher level of anemia is prevalent among older age women. He hypothesized that blood loss during frequent child births results in anemia in older age females. ${ }^{15}$

We observed that anemia was directly related to low socioeconomic status, low level of educational 
attainment in females. Majority $95.01 \%$ either never went to school or had only primary education in our study. Almost $71.70 \%$ females belong to very poor and poor socioeconomic status. Bekele observed that $18.7 \%$ had no formal education and $31 \%$ had achieved secondary school and above. $^{3}$ Olivia stated that poor household is indicator of poverty and the poverty leads to more prevalence of anemia. ${ }^{9}$ Bekele concluded that pregnant females with low income were four times more likely to develop anemia than high income group. ${ }^{3}$

We observed that majority of females (81.95\%) never practiced or infrequently practiced contraception. Females having two and more than two children were more anemic (79.01\%) than patients who were in their first pregnancy and had one child. Bekele reported that more than half of antenatal care patients, $202(60.8 \%)$ had history of good contraceptive use. ${ }^{3}$ He observed that family size is significantly associated with anemia, female patients with more than five children were prone to develop anemia. ${ }^{3}$ Obse also reported the same, big family size is associated with more anemic mothers. ${ }^{16}$

We observed that more than half of female patients were pregnant (63.43\%) and frequency of anemia was $60.28 \%$ and $94.20 \%$ were mild to moderately anemic and $46.28 \%$ were in their third trimester of pregnancy. Madiha reported that anemia also prevalent in women during their first pregnancy. ${ }^{17}$ Bekele reported pregnant females with less than two years inter pregnancy interval were more prone to develop anemia. ${ }^{3}$ Abdel Hafiz from Saudi Arabia observed high parity with frequent pregnancies make the females more likely to develop anemia. ${ }^{18}$

\section{CONCLUSION}

Frequency of anemia is very high in females presenting to tertiary care hospital being more common in younger age group. Frequent pregnancies, poverty and poor socioeconomic status were the major determinants of anemia in females.

Copyright@ 23 June, 2020.

\section{REFERENCE}

1. World Health Organization: Comprehensive Implementation Plan on Maternal, Infant and Young Child Nutrition. In. Geneva, Switzerland: WHO; 2014.

2. WHO. Micronutrients Indicators Haemoglobin Concentrations for the Diagnosis of Anemia and Assessment of Severity. Vitamin and Mineral Nutrition Information System; 2011.

3. Bekele A, Tilahun M, Mekuria A. Prevalence of anemia and Its associated factors among pregnant women attending antenatal care in health institutions of Arba Minch town, Gamo Gofa Zone, Ethiopia: A Cross-sectional study. Anemia. 2016 Jan 1;2016.

4. World Health Organization: Nutritional Anaemias: Tools for Effective Prevention and Control. In.: Geneva: World Health Organization; 2017.

5. Balarajan Y., Ramakrishnan U., Özaltin E., Shankar A. H., Subramanian S. V. Anaemia in low-income and middle-income countries. The Lancet. 2011; 378 (9809): 2123-2135. doi: 10.1016/S0140-6736(10)623045.

6. Ghazala MF, Zainab H, Samar I, Batha T. Iron deficiency anemia; dietary pattern of iron intake from indigenous iron rich food in female ida patients and corresponding hematological profiles: A cross sectional study at a tertiary care hospital in Karachi. Professional Med J. 2016; 23(09): 1092-8.

7. Faseeh S, Sehrish S, Aymen S, Fazli R. Frequency of anemia in patients presenting to tertiary care hospital in Peshawar, Pakistan Khyber Med Uni Med J. 2015; 7(1): 30-

8. Aqsa M, Shahid B, Sidra K, Humaira W. Determinants of anemia among pregnant females attending Sir Ganga Ram Hospital, Lahore Asian J Allied Health Sci. 2018; 3(1): 30-5.

9. Olivia Nankinga ${ }^{1}$ and Danstan Aguta. Determinants of anemia among women in Uganda: Further analysis of the Uganda demographic and health surveys BMC Public Health. 2019; 19: 1757. doi: 10.1186/s12889019-8114-1

10. Al-alimi AA, Bashanfer S, Morish MA. Prevalence of iron deficiency anemia among university students in Hodeida Province, Yemen. Anemia. 2018; 2018:7. doi: 10.1155/2018/4157876.

11. Habib MA, Black K, Soofi SB, Hussain I, Bhatti Z, Bhutta ZA, Raynes-Greenow C. Prevalence and predictors of Iron deficiency Anemia in children under five years of age in Pakistan, a secondary analysis of National Nutrition Survey Data 2011-2012. PLoS One. 2016; 
11(5):e0155051. doi: 10.1371/journal.pone.0155051.

12. Government of Uganda: National nutritional planning guidelines for Uganda. In. Kampala, Uganda; 2015.

13. USAID. USAID Uganda country development cooperation strategy 2016-2021. Uganda: Kampala; 2016.

14. India State-Level Disease Burden Initiative Malnutrition Collaborators. The burden of child and maternal malnutrition and trends in its indicators in the states of India: The Global Burden of Disease Study 19902017. Lancet Child Adolesc Health. 2019; 3(12): 855870. doi: 10.1016/S2352-4642(19)30273-1.

15. Kassebaum NJ, Jasrasaria R, Naghavi M, Wulf SK, Johns N, Lozano R, Regan M, Weatherall D, Chou DP, Eisele TP, et al. A systematic analysis of global anemia burden from 1990 to 2010. Blood. 2014; 123(5): 615-
624. doi: 10.1182/blood-2013-06-508325.

16. Obse N., Mossie A., Gobena T. Magnitude of anemia and associated risk factors among pregnant women attending antenatal care in Shalla Woreda, West Arsi Zone, Oromia Region, Ethiopia. Ethiopian Journal of Health Sciences. 2013; 23(2): 165-173.

17. Madiha A, Samina J, Asif $H$. Frequency of iron deficiency anemia in nulliparous pregnant females during last trimester. Pak J Med Health Sci. 2018; 12(1): 379-81.

18. Abdelhafez A. M., El-Soadaa S. S. Prevalence and risk factors of anemia among a sample of pregnant females attending primary health care centers in Makkah, Saudi Arabia. Pakistan Journal of Nutrition. 2012; 11(12):1113-1120. doi: 10.3923/ pjn.2012.1113.1120.

\section{AUTHORSHIP AND CONTRIBUTION DECLARATION}

\begin{tabular}{|c|l|l|l|}
\hline Sr. \# & Author(s) Full Name & \multicolumn{1}{|c|}{ Contribution to the paper } \\
\hline 1 & Saima Yasmin Qadir & $\begin{array}{l}\text { Data collection, Study design, } \\
\text { Interpretation, Principal Investigator, } \\
\text { Final reading. }\end{array}$ \\
\hline 2 & Hajira Sultana & $\begin{array}{l}\text { Data collection, Interpretation, } \\
\text { Principal investigator, final reading. }\end{array}$ \\
\hline 5 & Saima Ashraf & $\begin{array}{l}\text { Study design, interpretation, } \\
\text { Principal investigator, final reading. } \\
\text { Study design, interpretation, }\end{array}$ \\
6 & Shazia Siddiq & $\begin{array}{l}\text { Principal investigator, final reading. } \\
\text { Data collection, Study design, } \\
\text { Interpretation, Final reading. }\end{array}$ \\
\hline $\begin{array}{l}\text { Data collection, Study design, } \\
\text { Interpretation. }\end{array}$
\end{tabular}

